\title{
La fin du 9 h-18 h
}

Écrit par : Balázs Gyimesi, L'Observateur de l'OCDE

Dernière mise à jour : 8 novembre 2018

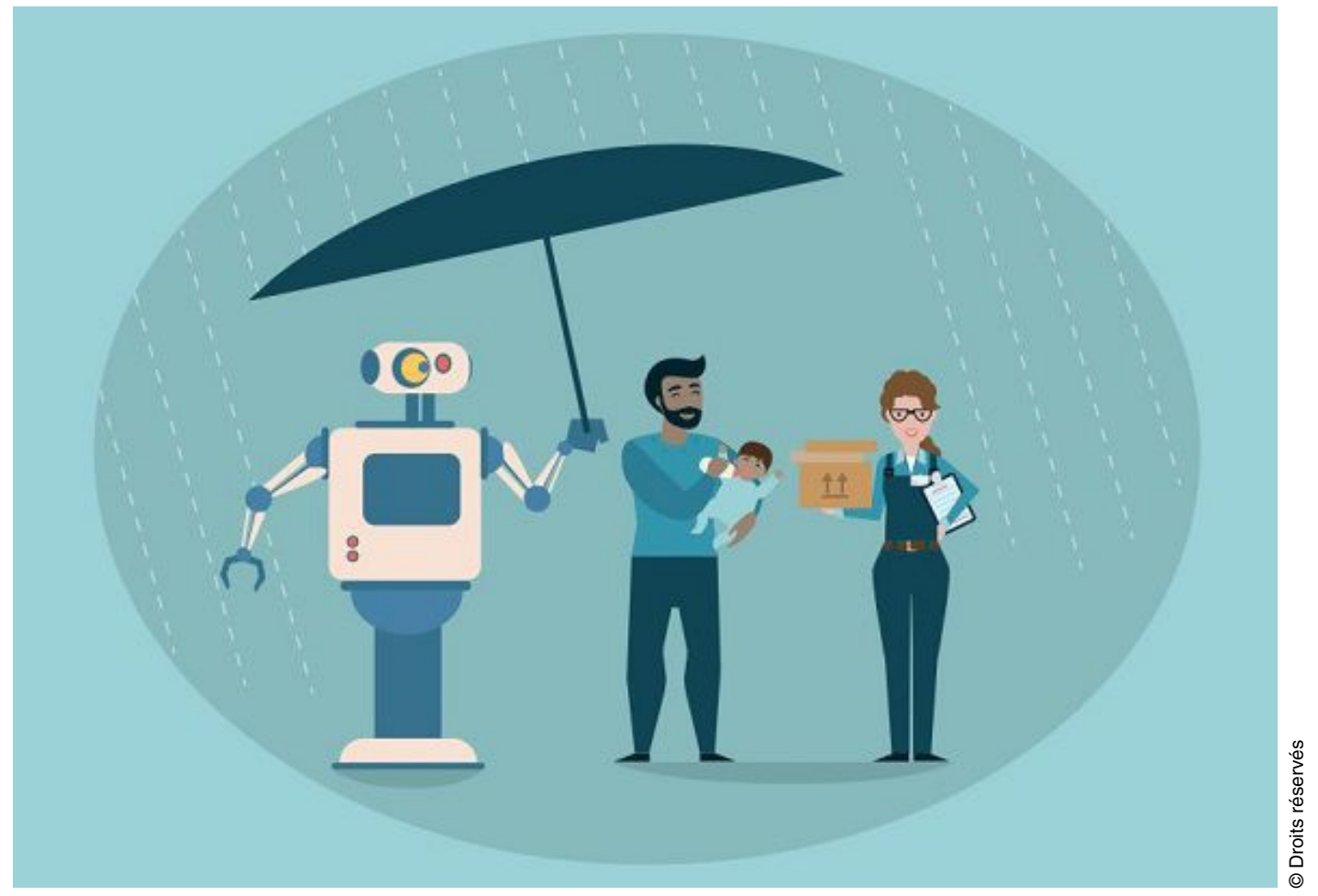

"Workin' 9 to 5; What a way to make a living " (Travailler de $9 \mathrm{~h}$ à $18 \mathrm{~h}$ : quelle belle façon de gagner sa vie), chantait Dolly Parton dans son titre à succès. Nous sommes en 1980 et le personnage qu'incarne Dolly Parton dans le film Comment se débarrasser de son patron fait figure de pionnier en expérimentant de nombreuses mesures emblématiques du monde du travail de demain, comme l'aménagement flexible du temps de travail ou le temps partagé. Certaines de ces mesures sont, depuis, devenus monnaie courante dans quelques pays et secteurs. Et, comme le montre le rapport de l'OCDE intitulé The Future of Social Protection: What Works for Non-standard Workers?, elles exercent une influence sur les politiques de protection sociale.

La plupart des systèmes de protection sociale ont été conçus en s'appuyant sur le modèle de l'emploi à temps plein, de $9 \mathrm{~h}$ à $18 \mathrm{~h}$. Mais l'essor de l'économie du " travail à la tâche " par l'intermédiaire des plateformes en ligne met en lumière les défaillances de ces systèmes en termes de couverture. En moyenne, dans 
l'OCDE, $16 \%$ de l'ensemble des travailleurs sont des indépendants et $13 \%$ de tous les salariés ont un contrat de travail temporaire. Nombre d'entre eux perçoivent un faible salaire et connaissent de fréquents épisodes de chômage. En toute logique, leurs perspectives de retraite ne sont guère réjouissantes non plus. Les pouvoirs publics l'ont compris et ont engagé des réformes afin d'améliorer la situation de ces travailleurs.

Prenons l'exemple de l'Italie, où les travailleurs indépendants dépendant économiquement d'un seul ou de quelques rares clients et désignés par le terme de «travailleurs parasubordonnés " représentaient près de $16 \%$ des nouveaux travailleurs en 2008. Dans les faits, ces indépendants sont " salariés " mais ils ne bénéficient ni du même contrat ni des mêmes avantages que les autres. Pourtant, ils sont nombreux à occuper ces emplois plusieurs années durant. En moyenne, les travailleurs parasubordonnés italiens sont qualifiés : $47 \%$ d'entre eux ont suivi des études supérieures. Grâce à des réformes publiques, le nombre de ces travailleurs diminue depuis 2008. La stratégie suivie par les pouvoirs publics prévoyait notamment l'augmentation progressive des taux de cotisation, la suppression de certains types d'accords contractuels et la réduction des avantages qu'offre le travail parasubordonné aux employeurs.

Dans le nouveau monde du travail, des politiques comme celles-ci peuvent contribuer à améliorer la qualité de vie des travailleurs, y compris de ceux qui sortent du schéma « 9 h-18 h » traditionnel.

CL'Observateur de l'OCDE, n³16, T4 2018

\section{Références}

OCDE (2018), The Future of Social Protection: What Works for Non-standard Workers?, Éditions OCDE, Paris, http://dx.doi.org/ 